\title{
Correlation of hypoxia status with radiosensitizing effects of sodium glycididazole: A preclinical study
}

\author{
YANG YU ${ }^{1}$, XIAOLIN LI ${ }^{1}$, HENGWEI XU ${ }^{2}$, JING LIU $^{1}$, MIN DONG $^{3}$, \\ JIA YANG ${ }^{1}, \mathrm{LU} \mathrm{SUN}^{4}$, XIAORONG SUN ${ }^{4}$ and LIGANG XING ${ }^{1}$ \\ ${ }^{1}$ Department of Radiation Oncology, Shandong Key Laboratory of Radiation Oncology; ${ }^{2}$ Department of Pharmacology, \\ Shandong Cancer Hospital Affiliated to Shandong University, Shandong Academy of Medical Science, Jinan, \\ Shandong 250117; ${ }^{3}$ Department of Oncology, Pingyi County People's Hospital, Linyi, Shandong 273300; \\ ${ }^{4}$ Department of Radiology, Shandong Cancer Hospital Affiliated to Shandong University, \\ Shandong Academy of Medical Science, Jinan, Shandong 250117, P.R. China
}

Received April 25, 2016; Accepted July 14, 2017

DOI: $10.3892 / \mathrm{ol} .2018 .8096$

\begin{abstract}
The correlation of pretreatment hypoxia status with the radiosensitization effect of sodium glycididazole $(\mathrm{CMNa})$ was not previously defined. The purpose of the present study was to evaluate the tumor hypoxia status in various cancer xenografts and to investigate the correlation between tumor hypoxia status and radiosensitizing effects of CMNa based on the pharmacokinetic and pharmacodynamic parameters. Human esophageal cancer (EC109), head and neck cancer (FaDu) and lung cancer (A549) nude mice xenografts were used. The concentrations of $\mathrm{CMNa}$ and its metabolites in the tumors and normal tissues were determined by high-performance liquid chromatography following intravenous injection of 171.9, 57.3 or $19.1 \mathrm{mg} / \mathrm{kg} \mathrm{CMNa}$. The tumors were irradiated with $30 \mathrm{~Gy}$ in 6 fractions with $\mathrm{CMNa}$ administration prior to each irradiation. The tumor growth delay values were calculated for each treatment group and compared with groups treated with radiation alone. Tumor hypoxia status was verified by immunohistostaining of tissues for hypoxia inducible factor $1 \alpha$ (HIF-1 $\alpha$ ) staining, and the concentration of plasma osteopontin (OPN) was determined using ELISA. The correlation between OPN concentration and tumor growth delay was subsequently analyzed. It was observed that the drug concentration in the tumor was 1.6-2.8 times higher compared with adjacent muscle, particularly at high and medium doses. CMNa was able to sensitize tumors to irradiation, particularly for EC109 and $\mathrm{FaDu}$ xenografts at high dose $(\mathrm{P}<0.05)$. Furthermore,
\end{abstract}

Correspondence to: Dr Ligang Xing, Department of Radiation Oncology, Shandong Key Laboratory of Radiation Oncology, Shandong Cancer Hospital Affiliated to Shandong University, Shandong Academy of Medical Science, 440 Jiyan Road, Jinan, Shandong 250117, P.R. China

E-mail: xinglg@medmail.com.cn

Key words: hypoxia, radiosensitizing, sodium glycididazole, osteopontin there was markedly increased expression of HIF-1 $\alpha$ and plasma OPN levels in FaDu and EC109 xenografts compared with A549. Additionally, it was indicated that pretreatment hypoxia status might be correlated with the radiosensitizing effects of CMNa. The present data demonstrated that tumor hypoxia status might be correlated with the radiosensitizing effects of $\mathrm{CMNa}$ in different tumor models.

\section{Introduction}

It is well established that human solid tumors frequently contain a substantial fraction of hypoxic cells. Hypoxia is a direct cause of resistance to radiotherapy and the majority of chemotherapeutic agents (1). In addition, hypoxia can lead to a more aggressive tumor phenotype (2). It has been demonstrated that the presence of measurable hypoxia is associated with poor outcome in many types of tumor (3-5). Since the mid 1970 's, clinical research in overcoming tumor hypoxia was mainly focus on the use of nitroimidazoles and its derivatives as hypoxic cell sensitizers (6,7). Several compounds have been developed for hypoxia detection (misonidazole and pimonidazole) and radiosensitization (etanidazole and nimorazole) in clinical settings $(8,9)$.

The randomized double-blind phase III study (DAHANCA 5 trial) demonstrated that nimorazole significantly improved the effect of radiotherapy for head and neck carcinoma (10). However, the randomized multicenter study of nimorazole concomitant with accelerated radiotherapy in head and neck squamous cell carcinoma was incomplete, and the number of patients involved in the study was small. Nevertheless, the results suggested an improvement in loco-regional tumor control and overall survival with given nimorazole in addition to accelerated fractionation radiation therapy (8).

Hypoxic radiosensitizers have also been successfully developed in China. Sodium glycididazole $\left(\mathrm{C}_{18} \mathrm{H}_{22} \mathrm{~N}_{7} \mathrm{NaO}_{10} \cdot 3 \mathrm{H}_{2} \mathrm{O}\right.$; also called $\mathrm{CMNa}$ ) was approved by the China Food and Drug Administration (11). Preliminary study indicated that $\mathrm{CMNa}$ was able to improve short-term locoregional control and was well tolerated in patients with locoregionally advanced laryngeal cancer (12). The phase II randomized trial demonstrated 
that CMNa was able to improve curative effects without increasing adverse side effects when treating patients with locally advanced nasopharyngeal carcinoma (13).

Ample data exist to support a high level of evidence for the benefit of hypoxic modification (5-15). However, hypoxic modification remains to have less impact on general clinical practice (16). One of main reason for this is the difficulty in detecting clinical status of tumor hypoxia and its correlation with the radiosensitizing effect of the target agent. Retrospective analysis of DAHANCA 5 trial also revealed that high concentrations of plasma osteopontin (OPN) might be useful in identifying patients who would benefit from modification of hypoxia (17). However, Lim et al (18) reported that high plasma OPN levels were not predictive of benefit with hypoxic cell cytotoxin, tirapazamine (TPZ). However, the correlation of pretreatment hypoxia status with radiosensitization effects was not defined in the study.

In the present study, the pharmacokinetics and pharmacodynamics of $\mathrm{CMNa}$ in different human cancer xenografts were evaluated, and whether tumor hypoxia status is correlated with the radiosensitizing effect of CMNa was investigated.

\section{Materials and methods}

Drug and chemicals. CMNa and its main metabolite, metronidazole, were provided by Luye Pharmaceutical Co., Ltd (Yantai, Shandong, China). Analytical grade methanol, acetonitrile and oxamide were purchased from Zhaoshang Industry and Trade Ltd. (Shanghai, China). CMNa was dissolved in saline $(0.9 \% \mathrm{NaCl})$ to the required concentration and stored at $4^{\circ} \mathrm{C}$ in the dark for subsequent experiments.

Cell culture. Human esophageal carcinoma cell EC-109, lung carcinoma cell A549, and squamous cell FaDu were purchased from the Chinese Academy of Sciences, Shanghai Institute of Cell Bank (Shanghai, China) and cultured in Dulbecco's modified Eagle's medium (DMEM, Gibco; Thermo Fisher Scientific, Inc., Waltham, MA, USA) supplemented with $10 \%$ fetal bovine serum (Gibco; Thermo Fisher Scientific, Inc.) and penicillin $(100 \mathrm{U} / \mathrm{ml})$ with streptomycin $(100 \mu \mathrm{g} / \mathrm{ml})$. Cultures were kept in a humidified atmosphere of $95 \%$ air and $5 \% \mathrm{CO}_{2}$ incubator at $37^{\circ} \mathrm{C}$.

Animal xenograft. The female mice (nu/nu, 18-22 g; 4-6 weeks old) were obtained from Huafukang Biotechnology Co., Ltd., (Beijing, China). The total number of mice used was 500-600. Housing conditions were as follows: Sealed plastic cage with air filter, no pathogen condition room, temperature

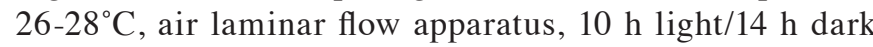
cycle, sterilized food and water. All animal experimental protocols were approved by the Institutional Animal Experimentation Committee of Shandong Cancer Hospital (Shandong, China). Tumor xenografts were formed by injecting $5 \times 10^{6}$ cells subcutaneously into the right hind legs of the mice. Each tumor was measured with digital caliper in three orthogonal dimensions ( $\mathrm{a}, \mathrm{b}$ and $\mathrm{c}$ ). Tumor volume was calculated as $\pi \mathrm{abc} / 6$. Experiments were performed when the tumors reached a volume of $\sim 500 \mathrm{~mm}^{3}$ for the pharmacokinetics study, or a volume of $\sim 150 \mathrm{~mm}^{3}$ for the tumor growth delay study.
Blood sample preparation. CMNa solution $(171.9,57.3$ or $19.1 \mathrm{mg} / \mathrm{kg}$ ) was injected through the tail vein of the mice bearing EC109 xenografts. The blood was collected from eye vein under anesthesia at $0.5,1,2,3,4,5,10,15,30,60,120$ and 240 min following injection (five or six animals were used for each time point). The blood sample was mixed with $3 \%$ (v/v) sodium heparin immediately. Subsequently, $0.2 \mathrm{ml}$ acetonitrile was added and then centrifuged $\left(25^{\circ} \mathrm{C}, 1,200 \mathrm{x} \mathrm{g}\right.$, 2-3 min). All steps were carried out under dark conditions.

Normal tissue and tumor sample preparation. Mice bearing EC109, A549 or FaDu xenografts were injected through the tail vein with $\mathrm{CMNa}(171.9,57.3$ or $19.1 \mathrm{mg} / \mathrm{kg})$. Tissues (tumor, muscle, heart, liver, spleen, lungs, kidneys, brain, bile and intestine) of each mouse was rapidly excised following sacrifice at 2, 5, 10, 20, 30, 40, 50, 60, 70, 80, 90, 100, 110 and $120 \mathrm{~min}$, respectively. The samples were washed twice with $0.9 \%$ saline, wiped with filter paper, weighed and homogenized with $0.9 \%$ saline to the same weight of tissues. Homogenates were spiked with oxamide $(0.2 \mathrm{ml})$ and grinded. Following centrifugation for $2 \min \left(25^{\circ} \mathrm{C}, 1,200 \mathrm{x} \mathrm{g}\right)$, $20 \mu 1$ supernatant was injected into the high-performance liquid chromatography (HPLC) system for analysis. All the processes were performed rapidly in the dark. A total of five animals were used for each time point.

HPLC. The HPLC system (Dionex; Thermo Fisher Scientific, Inc.) consisted of a DGP-3600A pump, a VW-3100 detector and a TCC-3000 column ( $4.6 \times 250 \mathrm{~mm}$; particle size, $5 \mu \mathrm{m})$. The mobile phase consisted of a mixture of methanol and ammonium oxalate solution $0.02 \mathrm{~mol} / \mathrm{l}(40: 60 \mathrm{v} / \mathrm{v})$, and the elution was performed at $30^{\circ} \mathrm{C}$ at a flow rate of $1.0 \mathrm{ml} / \mathrm{min}$. $\mathrm{CMNa}$ and its metabolites were detected using a UV detector at $320 \mathrm{~nm}$ and quantified by peak area. The CMNa blood concentration-time data were simulated using the $3 \mathrm{p} 87$ software (Pharmacological Society of China, Beijing, China) and fitted to a linear open two-compartment model.

Tumor irradiation and growth delay assay. The tumors were irradiated under anesthesia using the X-ray irradiator (X-rad225Cx; National Instruments Corp, Austin, TX, USA). A total of 30 Gy in 6 fractions (5 Gy every other day) were delivered in 3 weeks. Tumor bearing mice were injected intravenously with $\mathrm{CMNa}$ at a dose of 171.9, 57.3, or $19.1 \mathrm{mg} / \mathrm{kg} 30 \mathrm{~min}$ prior to irradiation. The mice received radiation alone, and those that were not treated were used as the control. The relative tumor volume (RTV) was calculated as $\mathrm{RTV}=\mathrm{Vt} / \mathrm{V}_{0}$, where $\mathrm{Vt}$ is the tumor volume at any given time and $\mathrm{V}_{0}$ is the volume at the time of initial treatment. The tumor growth time (TGT) was defined as the time required following the first day of treatment for a tumor to reach twice the initial volume, and the tumor growth delay time (TGDT) was defined as the TGT in each treated mouse minus the mean TGT in the control group. A total of six animals were used in each group.

Plasma osteopontin concentration test. Prior to the start of the first irradiation, the blood of tumor-bearing mice (50 $\mu \mathrm{l})$ was collected from the oculi rimae of mice. The plasma samples were centrifuged at $300 \mathrm{x} \mathrm{g}$ and $25^{\circ} \mathrm{C}$ for $10 \mathrm{~min}$ and 
Table I. Main pharmacokinetic parameters of $\mathrm{CMNa}$.

\begin{tabular}{lrcc}
\hline & \multicolumn{3}{c}{$\mathrm{CMNa}(\mathrm{mg} / \mathrm{kg})$} \\
\cline { 2 - 4 } Parameter & 171.9 & 57.3 & 19.1 \\
\hline $\mathrm{A}$ & 734.99 & 107.148 & 12.011 \\
$\alpha$ & 0.906 & 1.131 & 2.367 \\
$\mathrm{~B}$ & 0.01 & 19.504 & 2.544 \\
$\beta$ & 0.01 & 1.131 & 0.588 \\
$\mathrm{Vd} / \mathrm{l} / \mathrm{kg}$ & 0.234 & 0.452 & 1.312 \\
$\mathrm{C}_{\mathrm{max}} / \mathrm{mg} / \mathrm{l}$ & 466.79 & 71.27 & 5.575 \\
$\mathrm{~T}_{1 / 2} \alpha, \mathrm{min}$ & 0.765 & 0.613 & 0.293 \\
$\mathrm{~T}_{1 / 2} \beta, \mathrm{min}^{-1}$ & 69.315 & 0.613 & 1.179 \\
$\mathrm{~K} 10, \mathrm{~min}^{-1}$ & 0.602 & 0.663 & 1.04 \\
$\mathrm{~K} 12, \mathrm{~min}^{-1}$ & 0.304 & 0.467 & 1.017 \\
$\mathrm{~K} 21, \mathrm{~min}^{-1}$ & 0.01 & 1.131 & 0.899 \\
$\mathrm{AUC}, \mathrm{mg}^{-\mathrm{min}}$ & 802.008 & 122.163 & 9 \\
$\mathrm{CL}, \mathrm{min} / \mathrm{kg}$ & 0.141 & 0.3 & 1.364 \\
\hline
\end{tabular}

A, hybrid parameter; $\alpha$, distribution rate constant; $\mathrm{B}$, hybrid parameter; $\beta$, Elimination rate constant; $\mathrm{Vd}$, apparent volume of distribution; $\mathrm{C}_{\max }$, maximum concentration; $\mathrm{T} 1 / 2 \alpha$, plasma half-life for distribution phase; T1/2 $\beta$, plasma half-life for elimination phase; K10, first-order elimination rate constant; $\mathrm{K} 12$, transport rate constant from central compartment to periphery compartment; $\mathrm{K} 21$, transport rate constant from periphery compartment to central compartment; AUC, area under the curve; CL, total body clearance; CMNa, sodium glycididazole.

supernatant $(20 \mu \mathrm{l})$ was collected and stored. The concentration of OPN was quantified by ELISA using the OPN test kit (JK0235; Meilian Biological Ltd., Shanghai, China) according to the manufacturer's instructions.

Immunohistochemical staining of HIF-1 $\alpha$. Following excision, the tumors were fixed overnight (within $12 \mathrm{~h}$ at $25^{\circ} \mathrm{C}$ ) in $10 \%$ formalin and embedded in paraffin blocks, from which $4 \mu \mathrm{m}$ thick sections were prepared for immunohistochemical staining. To analyze the expression of HIF-1 $\alpha$, the slides were incubated with mouse monoclonal antibodies against HIF-1 $\alpha$ (WL01607; OriGene Technologies, Inc., Beijing, China) and secondary antibodies (IgG-horseradish peroxidase, WLA023; Leica Biosystems Newcastle Ltd., Newcastle, UK) diluted with PBS (29 g Na${ }_{2} \mathrm{HPO}_{4}, 3 \mathrm{~g} \mathrm{NaH}_{2} \mathrm{PO}_{4}, 85 \mathrm{~g} \mathrm{NaCl}$ dissolved in $500 \mathrm{ml}$ distilled water, fixed to $1,000 \mathrm{ml})$. Finally, the sections were stained with hematoxylin (10 min) and eosin (1-3 min) at room temperature. Ratios of positive HIF-1A staining and intensity were compared among different groups. The degree of staining score of positive cells was defined by counting 100 cells in the $\mathrm{x} 20$ field of view. The positive cell number $0-25,26-50,51-75$ and $76-100 \%$ was defined as $(-),(+),(++)$ and $(+++)$, respectively.

Statistical analysis. Analyses were performed using the Statistical Package for Social Sciences, (version 16.0; SPSS, Chicago, IL, USA). Quantitative data are expressed as the mean \pm standard error. Comparisons of histological parameters between groups were calculated using one-way analysis

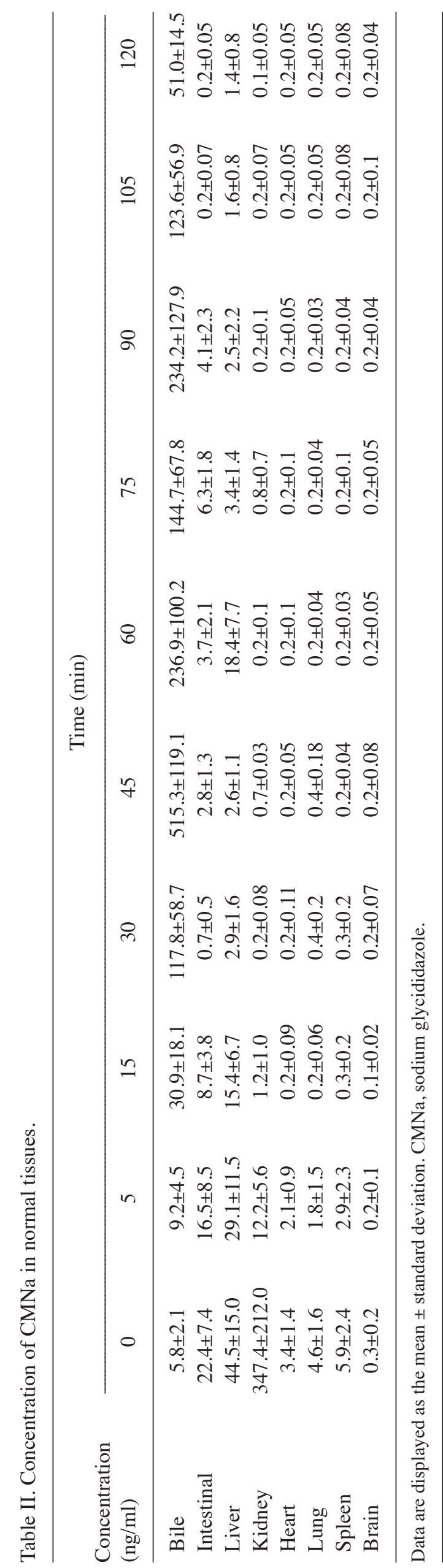



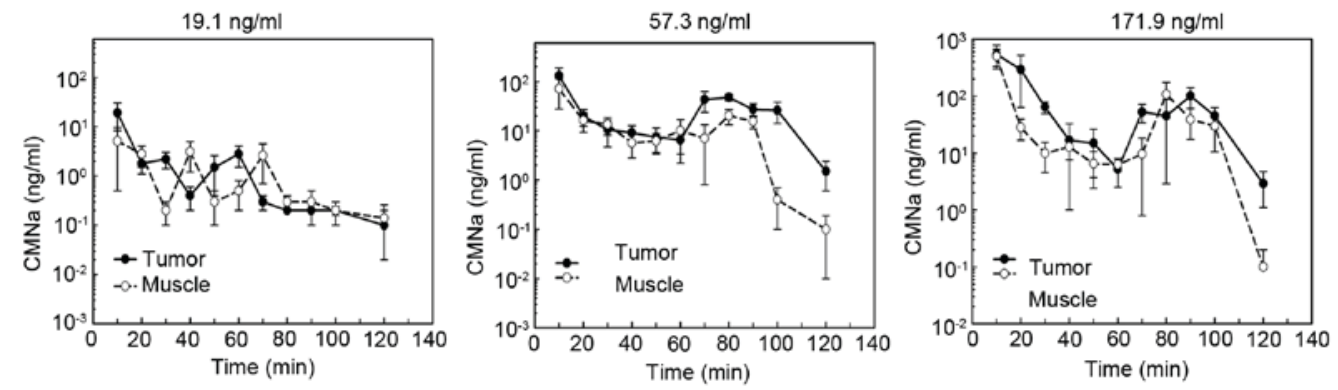

B: FaDu
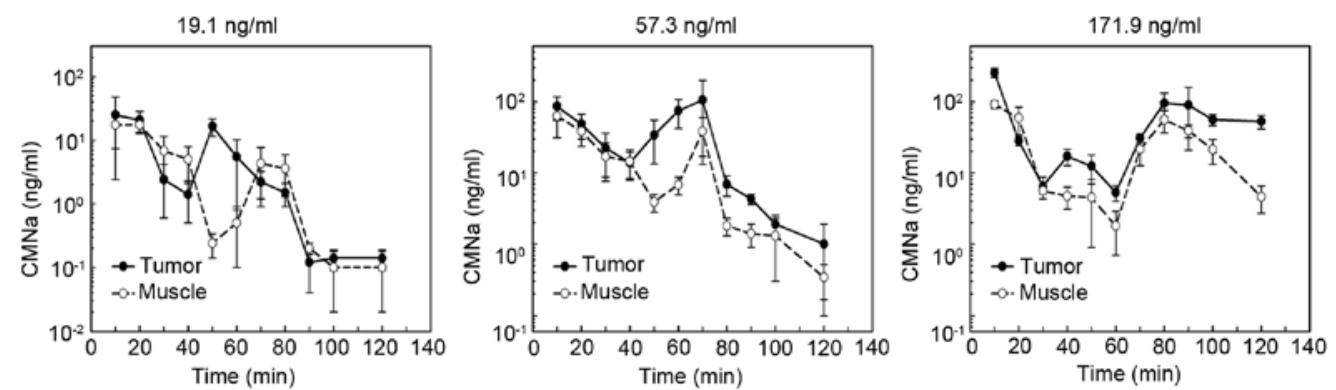

C: EC109
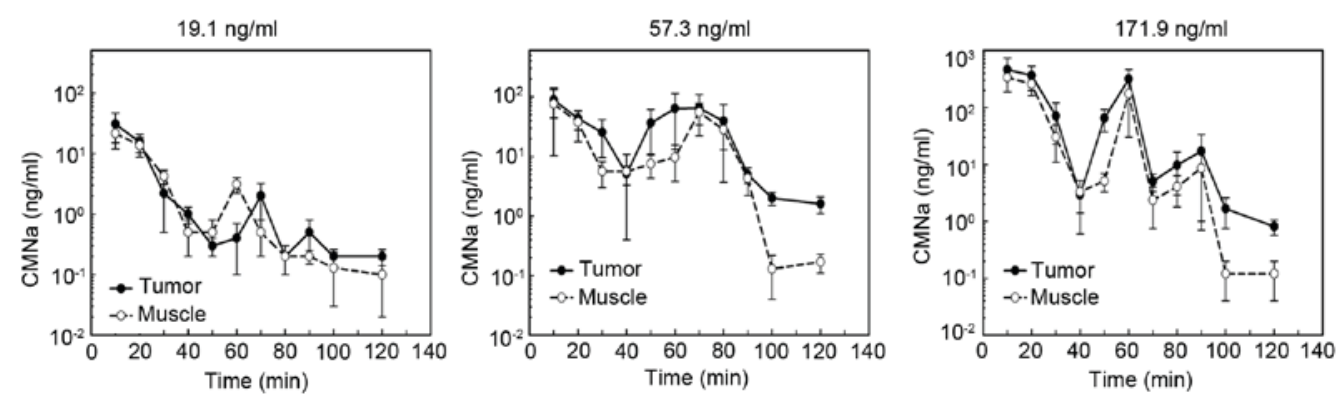

Figure 1. CMNa concentration in the tumors and adjacent muscle following intravenous injection of 171.9, $57.3 \mathrm{or} 19.1 \mathrm{mg} / \mathrm{kg}$ CMNa in mice bearing (A) A549, (B) $\mathrm{FaDu}$ or (C) $\mathrm{EC} 109$ xenografts. $\mathrm{n}=5$ for each time point; $\mathrm{CMNa}$, sodium glycididazole.

of variance followed by the Bonferroni post hoc test or the Mann-Whitney U-test. A Pearson's correlation coefficient and linear regression analysis were performed for analysis of the tumor growth delay assay and OPN concentration. All $\mathrm{P}$-values were two-sided, and $\mathrm{P}<0.05$ was considered to indicate a statistically significant difference.

\section{Results}

Serum concentrations of CMNa and metabolites. The chromatographic baseline characteristics of $\mathrm{CMNa}$ and its main metabolite, metronidazole, were far apart, with retention times 6.5 and $4.4 \mathrm{~min}$, respectively. No endogenous components interfered the analysis. The linearity of the calibration curve was determined with concentrations in the range of $0.269-68.8 \mathrm{ng} / \mathrm{ml}$ with a regression equation $\mathrm{Y}=0.0923+4.2352 \mathrm{X}(\mathrm{r}=0.9997, \mathrm{n}=5)$. The inter-day variation coefficients of $\mathrm{CMNa}$ were $<10 \%$ overnight, and the mean recovery was $88.1 \%$ for high concentration of CMNa. CMNa was rapidly eliminated from the blood, and the distribution half-life at three doses of CMNa were 0.765 , 0.613 and $0.293 \mathrm{~min}$, respectively. The relevant pharmacokinetic parameters were listed in Table I. The maximum CMNa concentration in blood $\left(\mathrm{C}_{\max }\right)$ and area under the curve (AUC) values were directly proportional to doses, which indicates first-order kinetics.

Distribution of CMNa in tumors and normal tissues. CMNa was distributed into the peripheral compartment $2 \mathrm{~min}$ following intravenous injection. A total of 5 min following CMNa administration, it was possible to detect $\mathrm{CMNa}$ in different organs (liver, intestine, kidney, lung, heart and brain), tumor adjacent tissues (muscle), and the tumors. The concentration of CMNa in the heart, liver, spleen, lungs, kidneys, brain, bile and intestine at different time points following intravenous administration determined by HPLC was listed in Table II.

The concentration of CMNa immediately following intravenous administration in the kidney was the highest, followed by intestinal, liver, heart, lung, spleen and brain tissues. A total 
Table III. Comparison of AUC values.

\begin{tabular}{|c|c|c|c|c|}
\hline Tumor & $\mathrm{CMNa}$ dose $(\mathrm{mg} / \mathrm{kg})$ & Tumor (AUC) & Muscle (AUC) & P-value \\
\hline \multirow[t]{3}{*}{ A549 } & 171.9 & $9039.3 \pm 805.7$ & $4979.7 \pm 513.1$ & 0.145 \\
\hline & 57.3 & $2631.7 \pm 213.8$ & $1303.6 \pm 139.8$ & 0.034 \\
\hline & 19.1 & $192.7 \pm 25.6$ & $128.7 \pm 20.6$ & 0.397 \\
\hline \multirow[t]{3}{*}{ EC109 } & 171.9 & $10832.0 \pm 1505.1$ & $6552.4 \pm 804.4$ & 0.022 \\
\hline & 57.3 & $3306.7 \pm 423.0$ & $1924.1 \pm 290.8$ & 0.023 \\
\hline & 19.1 & $375.2 \pm 57.0$ & $335.9 \pm 30.9$ & 0.415 \\
\hline \multirow[t]{3}{*}{$\mathrm{FaDu}$} & 171.9 & $4953.5 \pm 238.9$ & $2607.2 \pm 111.8$ & 0.068 \\
\hline & 57.3 & $3550.5 \pm 452.1$ & $1550.7 \pm 49.6$ & 0.032 \\
\hline & 19.1 & $632.9 \pm 70.5$ & $468.2 \pm 65.9$ & 0.339 \\
\hline
\end{tabular}

Data are displayed as the mean \pm standard deviation. AUC, area under the curve; CMNa, sodium glycididazole.

Table IV. Comparison of tumor growth delay time.

\begin{tabular}{|c|c|c|c|}
\hline Tumor type & Drug dose and treatment & TGDT, mean \pm standard error (days) & P-value \\
\hline \multirow[t]{4}{*}{ A549 } & RT alone & $2.91 \pm 0.54$ & 0.116 \\
\hline & $171.9 \mathrm{mg} / \mathrm{kg} ; \mathrm{CMNa}$ plus RT & $4.46 \pm 1.73$ & \\
\hline & $57.3 \mathrm{mg} / \mathrm{kg} ; \mathrm{CMNa}$ plus RT & $6.48 \pm 2.30$ & \\
\hline & $19.1 \mathrm{mg} / \mathrm{kg} ; \mathrm{CMNa}$ plus RT & $3.76 \pm 1.40$ & \\
\hline \multirow[t]{4}{*}{ EC109 } & RT alone & $1.60 \pm 0.44$ & 0.032 \\
\hline & $171.9 \mathrm{mg} / \mathrm{kg} ; \mathrm{CMNa}$ plus RT & $3.12 \pm 0.80$ & vs. RT alone 0.033 \\
\hline & $57.3 \mathrm{mg} / \mathrm{kg}$; CMNa plus RT & $2.04 \pm 0.41$ & vs. RT alone 0.604 \\
\hline & $19.1 \mathrm{mg} / \mathrm{kg} ; \mathrm{CMNa}$ plus RT & $2.70 \pm 0.52$ & vs. RT alone 0.721 \\
\hline \multirow[t]{4}{*}{$\mathrm{FaDu}$} & RT alone & $2.99 \pm 0.30$ & 0.007 \\
\hline & $171.9 \mathrm{mg} / \mathrm{kg} ; \mathrm{CMNa}$ plus RT & $7.47 \pm 1.54$ & vs. RT alone 0.032 \\
\hline & $57.3 \mathrm{mg} / \mathrm{kg}$; CMNa plus RT & $5.10 \pm 1.73$ & vs. RT alone 0.095 \\
\hline & $19.1 \mathrm{mg} / \mathrm{kg} ; \mathrm{CMNa}$ plus RT & $6.66 \pm 1.51$ & vs. RT alone 0.448 \\
\hline
\end{tabular}

CMNa, sodium glycididazole; RT, radiotherapy; TGDT, tumor growth delay time.

of 15 min following CMNa administration, the drug concentration significantly decreased and was very low in the kidney, spleen, heart, lung and brain. It was possible to detect $\mathrm{CMNa}$ again in intestinal and liver tissues approximately 60-80 min following injection, and the concentration-time curves were biphasic. After $120 \mathrm{~min}, \mathrm{CMNa}$ was undetectable in intestinal and liver tissues.

The levels of CMNa in the tumors were measured and compared with adjacent muscle in different tumor xenografts at high, medium and low doses of CMNa (Fig. 1). The AUC of drug concentration curves was compared among different tumor types and different drug groups. The results indicated that the drug concentration in the tumors was 1.6-2.8 times higher compared with muscle at the high and medium dose, but not in the low dose groups (Table III). The concentration-time curves of CMNa were biphasic, which were similar compared with those in the liver and intestine (Table II). The concentration decreased of CMNa quickly following injection, increased slightly at 60-80 min following injection and decreased to the lowest afterwards.
Radiosensitizing effects of CMNa. The radiosensitizing effects of CMNa were evaluated for three types of xenografts at three dose levels. It was demonstrated that CMNa was able to sensitize tumors to irradiation for all three cancer types (A549, FaDu and EC109) at different doses (Fig. 2). Tumor growth delay time (TGDT) was quantified and compared within the groups (Table IV). For EC109 and FaDu xenografts, TGDT in high dose groups was significantly longer compared with TGDT values in the irradiation control groups $(\mathrm{P}<0.05)$. However, these were no statistical differences between medium, low dose and irradiation control groups ( $\mathrm{P}>0.05)$. For A549 xenografts, no statistical differences were observed between high, medium, low dose groups and irradiation control groups $(\mathrm{P}>0.05)$.

OPN concentration and tumor HIF1- $\alpha$ expression. Tumor HIF1- $\alpha$ expression was evaluated by immunohistochemical staining for three types of xenografts ( $n=5$ for each type). Markedly increased HIF1- $\alpha$ expression were detected in $\mathrm{FaDu}$ $(3+, 70 \%)$ and EC109 $(2+\sim 3+, 50 \%)$ xenografts compared with A549 tumors $(1+, 40 \%)$, as shown in Fig. 3. 
A: $\quad$ A549

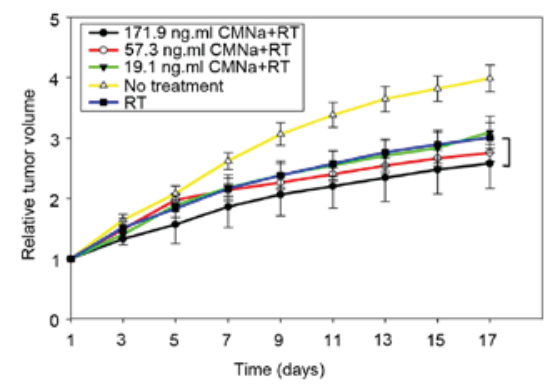

B: FaDu

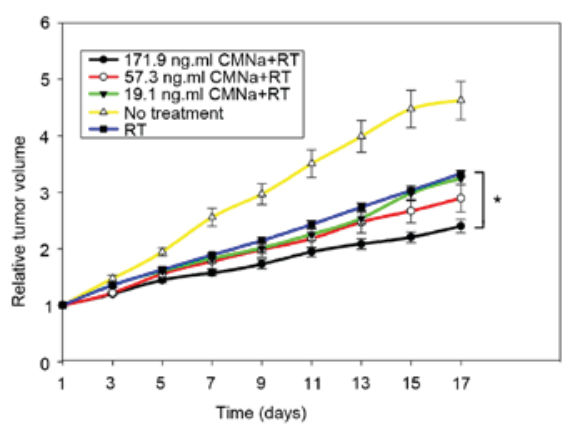

C: $\mathrm{EC} 109$

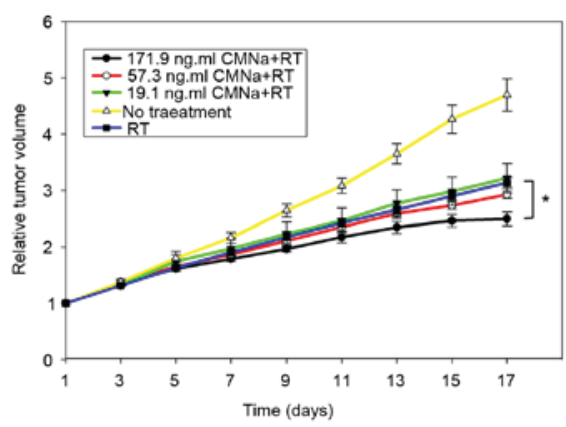

Figure 2. Tumor growth curves for mice bearing (A) A549, (B) FaDu or (C) EC109 xenografts. $\mathrm{n}=6$ for each group. $\mathrm{CMNa}$, sodium glycididazole; $\mathrm{RT}$, radiation therapy. ${ }^{\mathrm{P}}<0.05,171.9 \mathrm{ng} / \mathrm{ml} \mathrm{CMNa}+\mathrm{RT}$ vs. RT groups in $\mathrm{FaDu}$ and EC109 xenografts.

The median plasma concentration of OPN prior to the start of radiotherapy was $59.08 \mathrm{ng} / \mathrm{ml}(23.09-111.04 \mathrm{ng} / \mathrm{ml}), 60.33 \mathrm{pg} / \mathrm{ml}$ $(25.69-113.01 \mathrm{pg} / \mathrm{ml})$ and $51.99 \mathrm{pg} / \mathrm{ml}(16.99-93.72 \mathrm{pg} / \mathrm{ml})$ for EC109, FaDu and A549 tumor-bearing mice, respectively. The median OPN plasma level was used as a cut-off value. As shown in Fig. 4, mice with high OPN plasma levels had a better tumor local control after radiotherapy. However, the difference was not statistically significant $(\mathrm{P}=0.10,0.117$ and 0.374 for EC109, FaDu and A549, respectively).

\section{Discussion}

The novel hypoxic radiosensitizer, $\mathrm{CMNa}$, has been approved for use in combination with radiotherapy for the treatment of nasopharyngeal cancer in China $(10,11)$. Perspective trials for lung cancer and esophageal cancer have also been performed with encouraging results $(19,20)$. However, experimental data on CMNa, particularly on the in vivo pharmacokinetic and pharmacodynamic parameters in different tumor models were relatively limited. In the present preclinical study, it was confirmed that high doses of CMNa was able to sensitize human cancer xenograft to irradiation, particularly for head and neck cancer and esophageal cancer. The in vivo effects of CMNa might be associated with high tumor/muscle drug concentration ratio and high tumor hypoxia status (as detected by immunostaining for HIF-1 $\alpha$ ) in xenograft models. Furthermore, it was identified that plasma OPN concentration was correlated the radiosensitizing effect of $\mathrm{CMNa}$ in these tumor xenografts. The present study provided useful information to define optimal CMNa dose for personalizing radiosensization in further translational studies in different types of cancer.

Normal tissue toxicity of hypoxic radiosensitizing agents require attention in the clinical setting. In previous clinical phase I-III trials, the main side effects associated with the combination of CMNa and radiotherapy or chemoradiotherapy included mild gastrointestinal reactions (nausea, vomiting and constipation), mild reversible increases in serum alanine aminotransferase and bilirubin. Higher doses of $\mathrm{CMNa}$ and radiotherapy or chemoradiotherapy can also result in changes in cardiac function and electrocardiogram, including ST-T depression, arrhythmia and palpitation $(11,12,21)$. However, all the adverse effects were not statistically different from the control group $(11,12,21)$.

In present study, the distribution of levels of CMNa was verified in normal tissues and in tumor xenografts. Similar to a previous study (22), CMNa was eliminated quickly from blood and other organs, including the brain, heart and kidney. However, the concentration-time curves were biphasic in the intestinal and liver tissues. This indirectly confirmed that $\mathrm{CMNa}$ was excreted from the bile and re-absorbed from the intestines to the liver (liver-intestinal circulation). From a clinical point of view, this may lead to hepatotoxicity. Notably, Liu et al (21) reported a case of grade IV aminotransferase elevation in a trial for patients with nasopharyngeal carcinoma receiving $\mathrm{CMNa}$ during radiotherapy. This suggests that liver function should be monitored during CMNa administration, particularly for patients with active hepatitis.

Similar to other hypoxia radiosensitizers, $\mathrm{CMNa}$ was primarily investigated and clinically used in patients with head and neck cancer $(6,18)$. Clinical trials in esophageal cancer and lung cancer have also been performed $(19,20)$. In present study, significant radiosensitizing effects of CMNa were observed in xenografts of human head and neck, and esophageal cancer, but not in lung cancer. This finding was not surprising because greater intrinsic tumor hypoxia was observed in FaDu and EC109 tumors (Fig. 4). More importantly, mice blood OPN concentration may predict the radiosensitizing effects of CMNa. Mice blood OPN concentration may provide novel information, to enable the selection of patients for radiosensitizing based on tumor hypoxia condition, which had been retrospectively reported in randomized trials. For example, in DAHANCA 5 trial, elevated plasma OPN level was correlated with poorer disease-specific survival and only patients with high OPN level were able to benefit from nimorazole treatment (16). However, in another randomized trial, which investigated hypoxic cytotoxin TPZ, patient plasma OPN levels were not correlated with tumor control and survival (17). Le et al (23) evaluated 54 stage III-IV head and neck squamous cell carcinoma patients and reported OPN to be a hypoxia-regulated protein. Additionally, the levels 

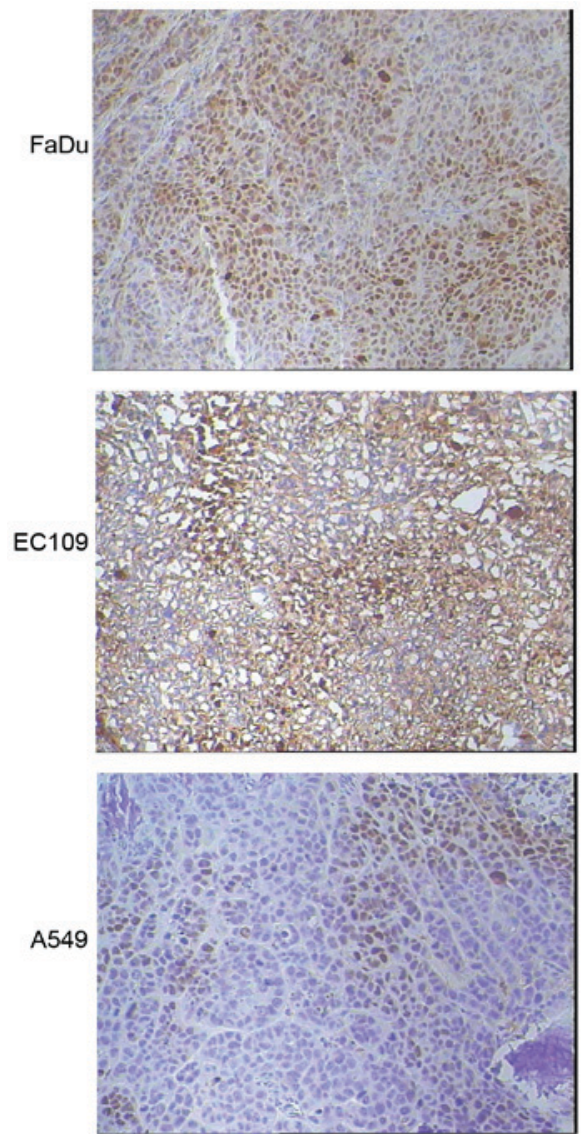

Figure 3. Representative hypoxia-inducible factor $1 \alpha$ immunohistostaining images for FaDu (+++), EC109 (++) and A549 (+) tumors. The positive cell number $0-25,26-50,51-75$ and $76-100 \%$ was defined as $(-),(+),(++)$ and $(+++)$, respectively.

of plasma OPN were correlated with tumor $\mathrm{pO}_{2}(23)$. The present authors also observed the positive correlation between tumor HIF-1 expression and OPN expression in esophageal cancer patients and nude mice xenografts (unpublished data). Therefore, further studies are required to define the correlation between hypoxia parameters (plasma OPN, hypoxia images and hypoxia gene expression profile) and the outcome of radiosensitizing treatment.

The findings of the present pre-clinical study are valuable for further clinical translational studies. Firstly, since only higher dose of CMNa exhibited significant radiosensitization for head and neck cancer, and esophageal cancer in the present study, dose escalation clinical trials may be considered in further studies. Secondly, in future clinical utilization, particularly in dose escalation study, hepatotoxicity must be considered. Finally, and most importantly, the hypoxia condition, either baseline or its kinetics, should be tested using hypoxia imaging or hypoxia-driven gene signatures/biomarkers $(24,25)$. This individualized radiosensitizing protocol should be developed in future randomized trials.

There are some limitations in the present study. Firstly, since CMNa has been previously tested during its early development phase in vitro study (26), this was not repeated. Secondly, it was not compared with other hypoxic radiosensitizing agents. Finally, the tumor hypoxia conditions were only tested by detecting the levels of plasma OPN and tissue HIF-1 $\alpha$
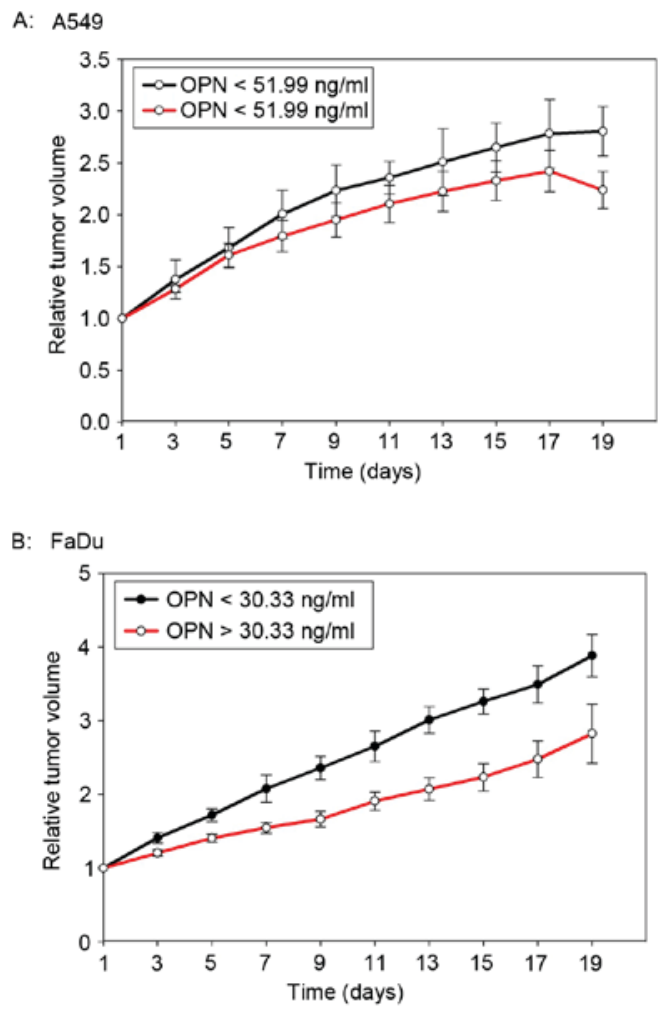

C: EC109

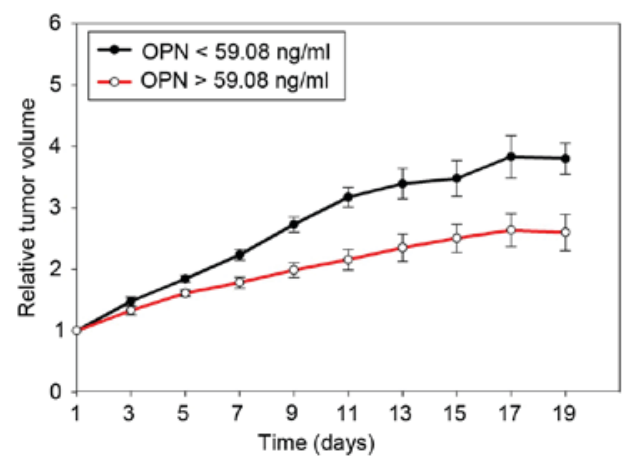

Figure 4. Tumor growth delay assay (relative tumor volume) in high OPN and low OPN groups for (A) A549, (B) FaDu or (C) EC109 xenografts. OPN, plasma osteopontin.

expression and not verified by other approaches, including hypoxia imaging or pimonidazole staining.

In summary, higher tumor CMNa drug concentration was detected in different tumor models. It was observed that $\mathrm{CMNa}$ was able to sensitize tumors to irradiation, particularly at high does for the treatment of head and neck, and esophageal cancer. Furthermore, the levels of tumor HIF-1 $\alpha$ and serum OPN concentration may be used to predict the radiosensitizing effects. These findings might be useful for future translational studies.

\section{Acknowledgements}

The present study was supported in part by the grant from the National Natural Science Foundation of China (grant no. 81272502) and from the Shandong Provincial Natural Science Foundation (grant no. ZR2015HZ004). Dr. Ligang Xing received a research fund from Luye Pharmaceutical Co., Ltd. (Yantai, Shandong, China). 


\section{References}

1. Tatum JL, Kelloff GJ, Gillies RJ, Arbeit JM, Brown JM, Chao KS Chapman JD, Eckelman WC, Fyles AW, Giaccia AJ, et al: Hypoxia: Importance in tumor biology, noninvasive measurement by imaging and value of its measurement in the management of cancer therapy. Int J Radiat Biol 82: 699-757, 2006.

2. Harris AL: Hypoxia-a key regulatory factor in tumour growth Nat Rev Cancer 2: 38-47, 2002.

3. Nordsmark M, Overgaard M and Overgaard J: Pretreatment oxygenation predicts radiation response in advanced squamous cell carcinoma of the head and neck. Radiother Oncol 41: 31-39, 1996.

4. Vaupel P and Mayer A: Hypoxia in cancer: Significance and impact on clinical outcome. Cancer Metastasis Rev 26: 225-239, 2007.

5. Fyles A, Milosevic M, Hedley D, Pintilie M, Levin W, Manchul L and Hill RP: Tumor hypoxia has independent predictor impact only in patients with node-negative cervix cancer. J Clin Oncol 20: 680-687, 2002.

6. Lee DJ, Moini M, Giuliano J, and Westra WH: Hypoxic sensitizer and cytotoxin for head and neck cancer. Ann Acad Med Singapore 25: 397-404, 1996.

7. Shibamoto Y, Takahashi M and Abe M: A phase I study of a hypoxic cell sensitizer KU-2285 in combination with conventional radiotherapy. Radiother Oncol 40: 55-58, 1996.

8. Hassan Metwally MA, Ali R, Kuddu M, Shouman T, Strojan P, Iqbal K, Prasad R, Grau C and Overgaard J: IAEA-HypoX. A randomized multicenter study of the hypoxic radiosensitizer nimorazole concomitant with accelerated radiotherapy in head and neck squamous cell carcinoma. Radiother Oncol 116: 15-20, 2015.

9. Drzymala RE, Wasserman TH, Won M, Shaw E, Cmelak AJ, Loeffler J and Souhami L; Radiation Therapy Oncology Group: A phase I-B trial of the radiosensitizer: Etanidazole (SR-2508) with radiosurgery for the treatment of recurrent previously irradiated primary brain tumors or brain metastases (RTOG Study 95-02). Radiother Oncol 87: 89-92, 2008

10. Overgaard J, Hansen HS, Overgaard M, Bastholt L, Berthelsen A, Specht L, Lindel $\varnothing v \mathrm{~B}$ and Jørgensen K: A randomized double-blind phase III study of nimorazole as a hypoxic radiosensitizer of primary radiotherapy in supraglottic larynx and pharynx carcinoma. results of the danish head and neck cancer study (DAHANCA) Protocol 5-85. Radiother Oncol 46: 135-146, 1998.

11. He ZY, Li FY, Tong Q, Liao ZW, Guan XX and Wang Y: Concurrent chemoradiotherapy with sodium glycididazole and cisplatin for local advanced nasopharyngeal carcinoma. Nan Fang Yi Ke Da Xue Xue Bao 28: 2038-2040, 2008 (In Chinese).

12. Zeng YC, Wu R, Xu ZG, Zhang XY, Fan GL, Wu LN, Wang YM, Hao SH, Zheng W, Chen XD, et al: Safety and radiation-enhancing effect of sodium glycididazole in locoregionally advanced laryngeal cancers previously treated with platinum-containing chemotherapy regimens: A preliminary report. Cancer Radiother 14: 59-64, 2010.

13. Li MY, Liu JQ, Chen DP, Qi B, Liang YY and Yin WJ: Glycididazole sodium combined with radiochemotherapy for locally advanced nasopharyngeal carcinoma. Asian Pac J Cancer Prev 15: 2641-2646, 2014.
14. Nordsmark M, Bentzen SM, Rudat V, Brizel D, Lartigau E, Stadler P, Becker A, Adam M, Molls M, Dunst J, Terris DJ and Overgaard J: Prognostic value of tumor oxygenation in 397 head and neck tumors after primary radiation therapy. An international multi-center study. Radiother Oncol 77: 18-24, 2005.

15. Koukourakis MI, Bentzen SM, Giatromanolaki A, Wilson GD, Daley FM, Saunders MI, Dische S, Sivridis E and Harris AL: Endogenous markers of two separate hypoxia response pathways (hypoxia inducible factor 2 alpha and carbonic anhydrase 9) are associated with radiotherapy failure in head and neck cancer patients recruited in the CHART randomized trial. J Clin Oncol 24: 727-735, 2006.

16. Overgaard J: Hypoxic radiosensitization: Adored and ignored. J Clin Oncol.25: 4066-4074, 2007.

17. Overgaard J, Eriksen JG, Nordsmark M, Alsner J, Horsman MR; Danish Head and Neck Cancer Study Group: Plasma osteopontin, hypoxia and response to the hypoxia sensitiser nimorazole in radiotherapy of head and neck cancer: Results from the DAHANCA 5 randomised double-blind placebo-controlled trial. Lancet Oncol 6: 757-764, 2005.

18. Lim AM, Rischin D, Fisher R, Cao H, Kwok K, Truong D, McArthur GA, Young RJ, Giaccia A, Peters L and Le QT: Prognostic significance of plasma osteopontin in patients with locoregionally advanced head and neck squamous cell carcinoma treated on TROG 02.02 phase III trial. Clin Cancer Res 18: 301-307, 2012.

19. Yang J, Liu MZ, Cai L, Hu YH, Liu H, Li QQ and Cui NJ: Phase II clinical trial of sodium glyci-didazole (CM-Na) combined with concurrent radiochemotherapy for advanced esophageal carcinoma. Ai Zheng 27: 622-666, 2008 (In Chinese).

20. Zhang Q, Wang DQ and Wu YF: Sodium glycididazole enhances the efficacy of combined iodine-125 seed implantation and chemotherapy in patients with non small-cell lung cancer. Oncol Lett 9: 2335-2340, 2015

21. Liu MZ, He LR, Lu TX, Chen YY, Hu YH, Cui NJ, Xu GZ, Gao L, Xiao GL, Zhang SW, et al: Effect of hypoxic radiosensitizer sodium glycididazole on long-term result of radiotherapy for nasopharyngeal carcinoma. Zhonghua Zhong Liu Za Zhi 28: 932-937, 2006 (In Chinese)

22. Liu CX, Wei GL and Xiao SH: Pharmacokinetics of sodium bimetrondazole glycinate in mice and rats. Yao Xue Xue Bao 35: 770-773, 2000 (In Chinese).

23. Le QT, Sutphin PD, Raychaudhuri S, Yu SC, Terris DJ, Lin HS, Lum B, Pinto HA, Koong AC and Giaccia AJ: Identification of osteopontin as a prognostic plasma marker for head and neck squamous cell carcinomas. Clin Cancer Res 9: 59-67, 2003.

24. Toustrup K, Sørensen BS, Lassen P, Wiuf C, Alsner J, Overgaard J and Danish Head and Neck Cancer Group (DAHANCA): Gene expression classifier predicts for hypoxic modification of radiotherapy with nimorazole in squamous cell carcinomas of the head and neck. Radiother Oncol 102: 122-129, 2012.

25. Tran LB, Bol A, Labar D, Cao-Pham TT, Jordan B, Grégoire V and Gallez B: Predictive value of (18)F-FAZA PET imaging for guiding the association of radiotherapy with nimorazole: A preclinical study. Radiother Oncol 114: 189-194, 2015.

26. Zheng XL, Gao JG and Zhang $\mathrm{H}$ : In vitro radiosensitization effect of sodium glycididazol on V79 cells. Journal of Radiation Research and Radiation Processing 13: 213-218, 1994 